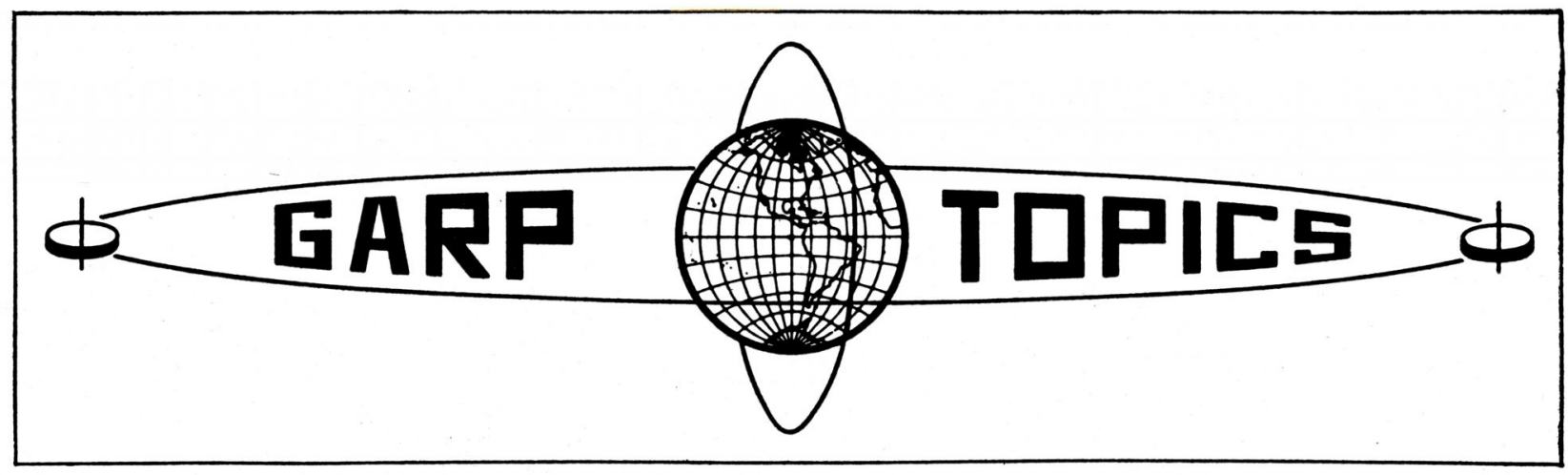

No. 30

December 1973

An occasional series reporting on U.S. and international GARP scientific, technical, and planning activities, developments, and programs, presented as a public service to the meteorological community by the American Meteorological Society through arrangements with the U.S. Committee on the Global Atmospheric Research Program of the National Academy of Sciences-National Research Council. Opinions expressed in GARP TOPICS do not necessarily reflect the point of view of the U.S. Committee.

\title{
Tibetan High and Upper Tropospheric Tropical Circulations during Northern Summer
}

\author{
T. N. Krishnamurti, S. M. Daggupaty, ${ }^{1}$ Jay Fein, ${ }^{2}$ Masao Kanamitsu, and John D. Lee ${ }^{1}$ \\ Department of Meteorology, Florida State University, Tallahassee, Fla. 32306
}

\begin{abstract}
The zonally asymmetric climatology of the tropical largescale motion field is an interesting GARP topic. Understanding of the maintenance of various quasi-stationary features will be a challenging problem during the FGGE (the First GARP Global Experiment) and Monex (the Monsoon Experiment). In this paper we present some current thoughts that are relevant to the climatology of the tropical upper troposphere during the northern summer.

A review of some of the results from various numerical general circulation models and theoretical studies is presented for northern summer conditions. The relative success or failure of simulations of $200-\mathrm{mb}$ climatology is discussed. It is pointed out that a proper simulation of the belt of anticyclones over the Asian highlands is somewhat crucial for a proper simulation of the summer climatology over the rest of the tropics.

Observations of the semipermanence of the Tibetan high pressure cell during northern summer at $200 \mathrm{mb}$ suggests that it acts somewhat like a barrier. In order to illustrate this we consider a problem related to the evolution of barotropic non-divergent flows past a barrier. The flows are initially zonal, with speeds varying in the north-south direction according to northern summer ob-
\end{abstract}

\footnotetext{
1 Present affiliation: National Center for Atmospheric Research, Boulder, Colo. 80302.

2 Present affiliation: Department of Meteorology, University of Oklahoma, Norman, Okla. 73069.
}

servations. The barrier, whose shape is based on observations of a blocking thermal high, is impulsively introduced at initial time. The flows are kept zonal at frictionless walls at $25 \mathrm{~S}$ and $45 \mathrm{~N}$. The initial north-south distribution of the zonal flows is shown to have no inflection point in its profile, thus it does not satisfy the necessary condition for barotropic instability. The presence of an impulsively introduced barrier, however, results in the evolution of transient as well as steady wave motions in long term numerical integrations. It is shown that a 30-day mean motion field contains many of the well known climatological features such as the African high, the mid-Atlantic trough, the mid-Pacific trough, the Mexican high and a weak easterly jet south of the Tibetan high. Calculations of kinetic energy exchanges between waves and zonal flow in this simple experiment is compared with corresponding calculations for tropical observations and recent general circulation experiments carried out by Abbott. The impulsively introduced barrier simulates an energy source for zonal wavenumber 1, quite similar to observations in a tropical belt. Although this experiment is fairly crude, it is found to be very illustrative in many respects. Many diverse experiments along these lines can be carried out to reveal various aspects of atmospheric circulations.

\section{Introduction}

An understanding of the large-scale circulation of the tropical upper troposphere is important to general circulation and climate studies. With the forthcoming 


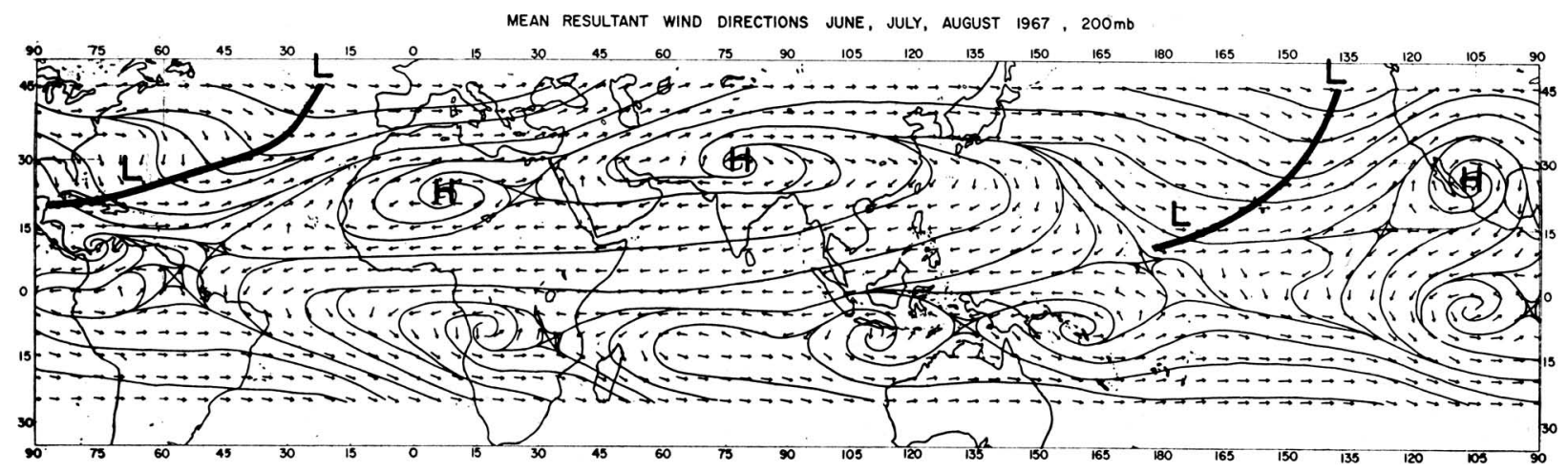

FIG. 1. Observed time averaged streamlines (June, July, and August 1967) at $200 \mathrm{mb}$. The principal circulation features ( $I$ ) discussed in text are indicated by letters $H$ and $L$ and trough lines.

global observational programs under GATE (GARP Atlantic Tropical Experiment), FGGE (First GARP Global Experiment) and Monex (Monsoon Experiment) we feel that important contributions will be made in this direction. Some preliminary remarks on the importance of this goal will be presented in this paper. We are interested in circulations during the northern summer for the tropical belt between $25 \mathrm{~S}$ and $45 \mathrm{~N}$ at the $200 \mathrm{mb}-\mathrm{level}$.

The primary entities of the large-scale circulations over the northern summer hemisphere are: i) Tibetan high, ii) African high, iii) Mexican high, iv) mid-Atlantic trough, v) mid-Pacific trough, and vi) easterly jet of southern Asia (Fig. 1). These features are observed on most daily maps as well as the mean maps.

Since we shall be frequently addressing ourselves to these primary features of the tropical upper troposphere, we shall use the symbol $I$, to denote them.

A zonal harmonic analysis of the observed motion field reveals that wavenumbers 1 and 2 carry a large proportion of the total variance (for the streamfunction) as indicated in Fig. 2 for 20N. Fig. 1 and Fig. 2 are from a recent study by Krishnamurti (1971a). Furthermore, it is noted that a large proportion of the total variance of these long waves is accounted for by the stationary part of the motion field. In Fig. 2 we may also note a peak around wavenumber 8 . This is contributed mostly by slow westward propagating disturbances on the 200mb surface.

Other important observational findings in this area are that long waves (wavenumbers 1 and 2) have a very pronounced southwest to northeast tilt. A consequence of this tilt is a removal of westerly momentum by eddies towards the summer pole. A correlation between the easterly flow and divergence of eddy flux of westerly momentum results in an energy exchange from the long waves to the easterly mean zonal flows. It is possible to examine energy exchanges among harmonic wave components. A study along these lines for the $200-\mathrm{mb}$ observations during the northern summer was carried out by Kanamitsu et al. (1972). The main results of the

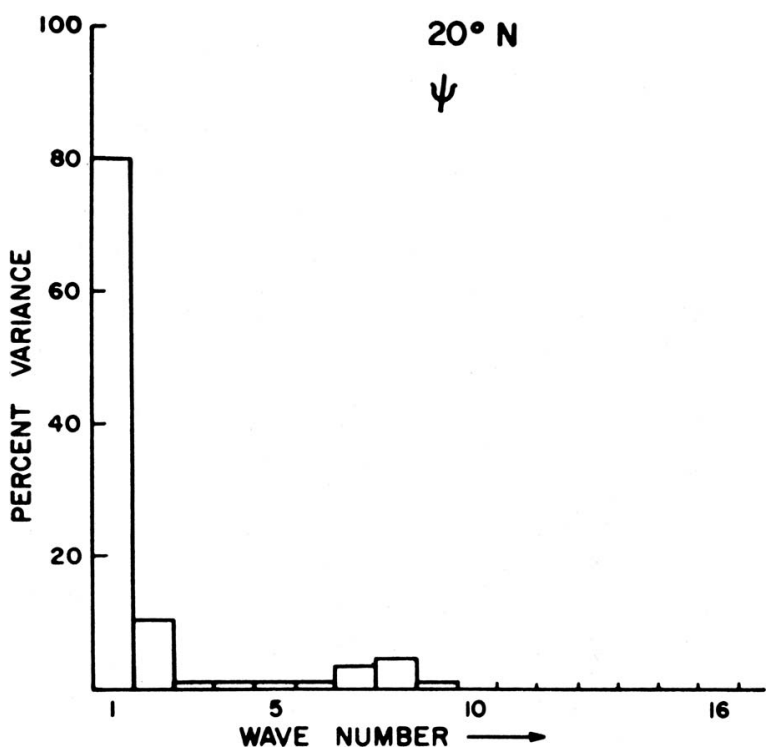

Fig. 2. Percent variance plotted against zonal wavenumber of the streamfunction $\psi$ at $200 \mathrm{mb}$. The variance is computed from daily fields of streamfunction and averaged over 92 days. Spectral analyses are at $20 \mathrm{~N}$.

energy exchanges are schematically shown in Fig. 3. Part of the results here are speculative and are indicated by question marks (?). Fig. 3 may be summarized as follows. The flows are somewhat arbitrarily divided into three categories, zonal $Z$, long (wavenumbers 1 and 2) $L$, and short (remaining waves) $S$.

The decomposition is illustrated for the kinetic and potential energy and the heating $H$ during northern summer, of which we regard the long wave heating $H_{L}$ as a primary heating function arising from land-ocean contrasts. It should be noted that $H_{L}$ is a net heating of the troposphere, e.g., sensible and evaporative fluxes from ocean and from land areas, long and short wave radiative effects, shallow and deep cumulus convection and large-scale condensation heating. A net generation of eddy available potential energy results from the heat- 


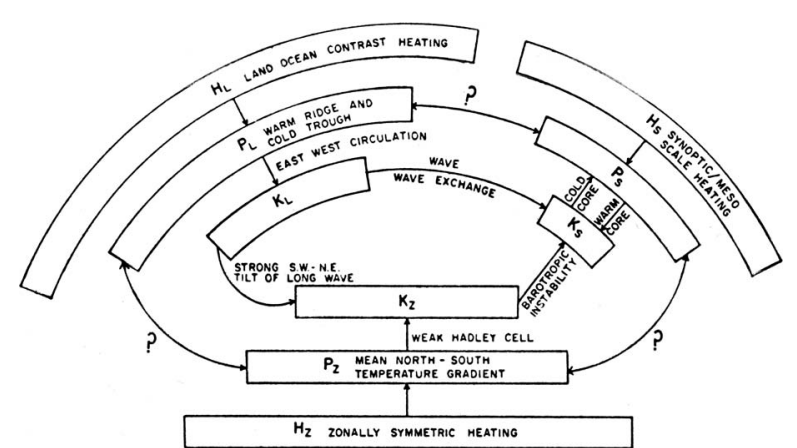

FIG. 3. A schematic diagram of energy exchanges among long waves $L$, short waves $S$, and zonal flows $Z$. $H$ stands for heating, $P$ for available potential energy, and $K$ for kinetic energy. There is some observational evidence for exchanges indicated by an arrow. Those indicated by a question mark (?) are uncertain.

ing function $H_{L}$. Kinetic energy on the scale of the long waves $K_{L}$ arise primarily from thermally direct eastwest vertical circulations. Most of this generation of $K_{L}$ is thus related to large east-west differential net heating primarily associated with zonal wavenumbers 1 and 2 . The diagram furthermore indicates that zonal flows receive kinetic energy, $K_{z}$, from the long waves and lose to shorter waves, $K_{\boldsymbol{s}}$ (see Kanamitsu et al., 1972, and Krishnamurti et al., 1973). This diagram is to be regarded as somewhat schematic because of uncertainties in most elements. Short waves, $K_{S}$, are shown to receive part of their energy from longer waves, $K_{L}$, via "wave-wave" interactions, from zonal flows, $K_{z}$, via barotropic instability of the zonal flows, and lose or gain from eddy potential energy, $P_{S}$, depending on whether the systems are thermally indirect or direct, respectively.

During the forthcoming observational programs under GARP, a detailed assessment of various components of the energetics would be highly desirable. Organization of cumulus convection evidently can be viewed on many different spatial scales, e.g., $10 \mathrm{~km}$ scale to $10^{4} \mathrm{~km}$ scale. It is important to understand the direct effects of the cumulus scales on the motion field in various scales. We feel that a zonally-asymmetric intertropical convergence zone can be viewed as an important organization of the cumulus motions on the planetary scale. As we have stated here, observational studies suggest that there is an important energy source in zonal wavenumbers 1 and 2 . We need to understand the relative roles of cumulus scales, shallow and deep convection, differential radiation, and boundary layer energy fluxes on the long planetary scales to define this energy source.

In this paper we shall briefly review some of the important general circulation studies that refer to circulation features, $I$. We shall next point out that a proper understanding of the planetary energy source is somewhat intimately related to a proper simulation of the belt of upper anticyclones over Asia, in particular the Tibetan high. The Tibetan high is a warm upper- tropospheric anticyclone whose formation during the southwest monsoon months is evidently related to the radiation budget of the warm earth's surface, which is determined in part by sensible and latent heat fluxes in the boundary layer, and to shallow and deep convection and radiative processes in the atmosphere. For the most part, the Tibetan high appears as a large-scale thermal mountain. On synoptic maps it appears in the form of a large blocking high. Flows in the tropical belt seem to be very largely influenced by this high, acting as a barrier. We shall show that a treatment of the Tibetan high as a barrier provides some understanding of the circulation features $I$.

Although the Tibetan high is found on most 200-mb maps during the northern summer season, it is observed to exhibit some interesting fluctuations in its intensity.

By tabulating a daily local mean value of the streamfunction over a region of the Tibetan high, a time-series analysis for 92 days during the summer of 1967 was performed. The results are shown in Fig. 4. This analysis reveals that there are two primary modes of time oscillation of the Tibetan high. These are around 3 days and 13 to 15 days. The 3-day mode is probably related to the life cycle of westward propagating monsoon depressions in the great plains over India. The data for the summer of 1967 from which this spectral analysis was obtained is indicated in Fig. 5. The linear trend in Fig. 5 indicates a seasonal build-up of the intensity of the Tibetan high, and had to be removed from the data prior to the spectral analysis shown in Fig. 4. We recognize this nonsteady nature of the Tibetan high.

\section{A review of general circulation models that refer to circulation features $(I)$}

a) Manabe et al. (1970a, b) have discussed briefly their "Princeton High Resolution GFDL" global general

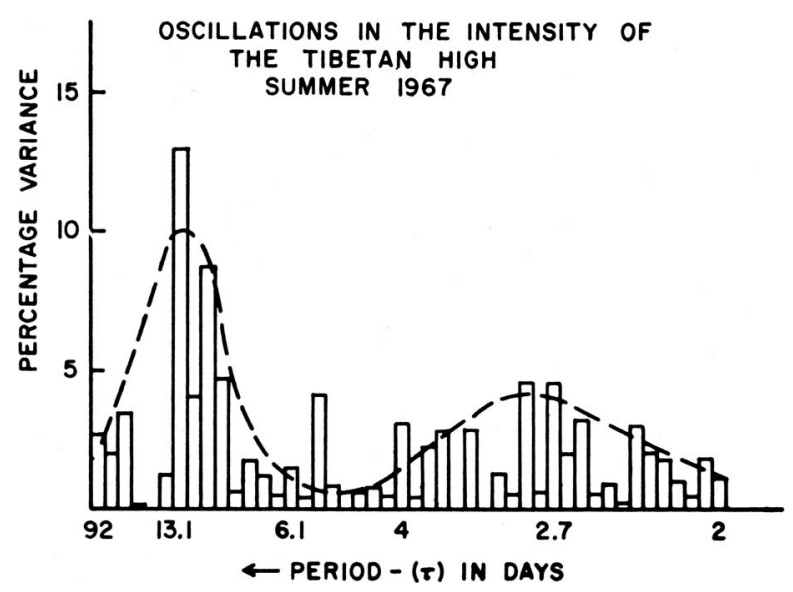

FIG. 4. A time series analysis of the oscillations of the Tibetan high (seasonal linear trend was removed from observations shown in Fig. 5). Percent variance is plotted against period. The dashed line is a smoothed envelope emphasizing the two modes of oscillation mentioned in the text. 
circulation model. This model has 96 grid points between the south and north pole. The grid distance over the tropics is of the order of $210 \mathrm{~km}$. Some of the principal ingredients of this model are:

1) Primitive equations in spherical coordinates.

2) Smoothed mountains included via use of the socalled sigma $(\sigma)$ coordinates.

3) Nine levels in the vertical.

4) Monthly mean solar insolation is made to vary from one month to the next.

5) Monthly mean climatological distribution of water vapor, carbon dioxide, ozone and cloud cover provides a month by month change in the forcing by longwave radiation.

6) Explicit calculation of heat and radiation balance of the continental surface yields a calculation of its temperature; use of the $\sigma$ coordinate provides an elevated heat source.

7) Normal distribution of monthly mean observed temperatures of the oceans is used as a lower boundary condition.

8) Moist convective adjustment.

9) Evaporation, sensible heat flux, and momentum flux across the ocean-atmosphere interface via simple bulk-aerodynamic principles.

Changes from one month to the next in some of the important forcing functions are introduced in this longterm general circulation experiment. Ocean temperature, convective adjustment, longwave radiation, land temperatures, and shortwave radiation provide an important zonally-asymmetric thermal forcing especially during the northern summer.

The results of this general circulation model (mostly unpublished at this time, Manabe and Hahn, 1973), are most promising over the tropics. Except for an unusually large frequency of typhoons on a daily basis which results in an intense upper high pressure belt at the 190-mb

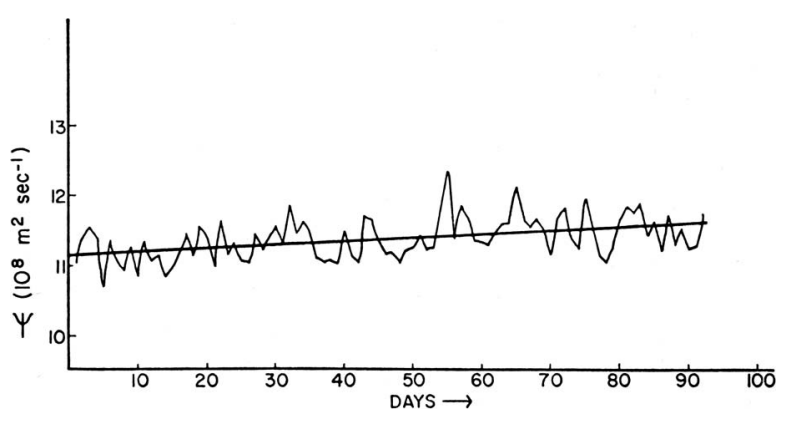

Fic. 5. Daily mean value of $200 \mathrm{mb}$ streamfunction averaged over the region $50 \mathrm{E}$ to $130 \mathrm{E}$ and $17 \mathrm{~N}$ and $35 \mathrm{~N}$. Days along abscissa indicate the 92-day period between June 1, 1967 and 31 August 1967. The sloping straight line indicates the linear trend. The ordinate is a measure of the intensity of the Tibetan high.

level over the western Pacific, most of the large-scale climatological features are surprisingly well depicted during northern summer by this model (see Fig. 6).

It should, however, be noted that occasional daily maps (Fig. 7) are quite similar to those one finds from analysis of observations at $200 \mathrm{mb}$ (Krishnamurti, 1971a). The wind fields for July 15 (Fig. 7) from the Princeton General Circulation Experiment, and their mean map (Fig. 6) both contain the principal circulation features $I$. In addition to these principal features, a number of transient features are present, again reminiscent of several such features on daily maps (Krishnamurti and Rodgers, 1970). Because of the rather detailed physics in this general circulation model, it may be somewhat difficult to isolate the important effects that determine these primary climatological features.

b) A somewhat simpler approach for the understanding of northern summer climatology of the tropical uppertropospheric motion field is presented by Abbott (1973). One of his main conclusions is that these semipermanent features form as a result of large-scale, east-west heating

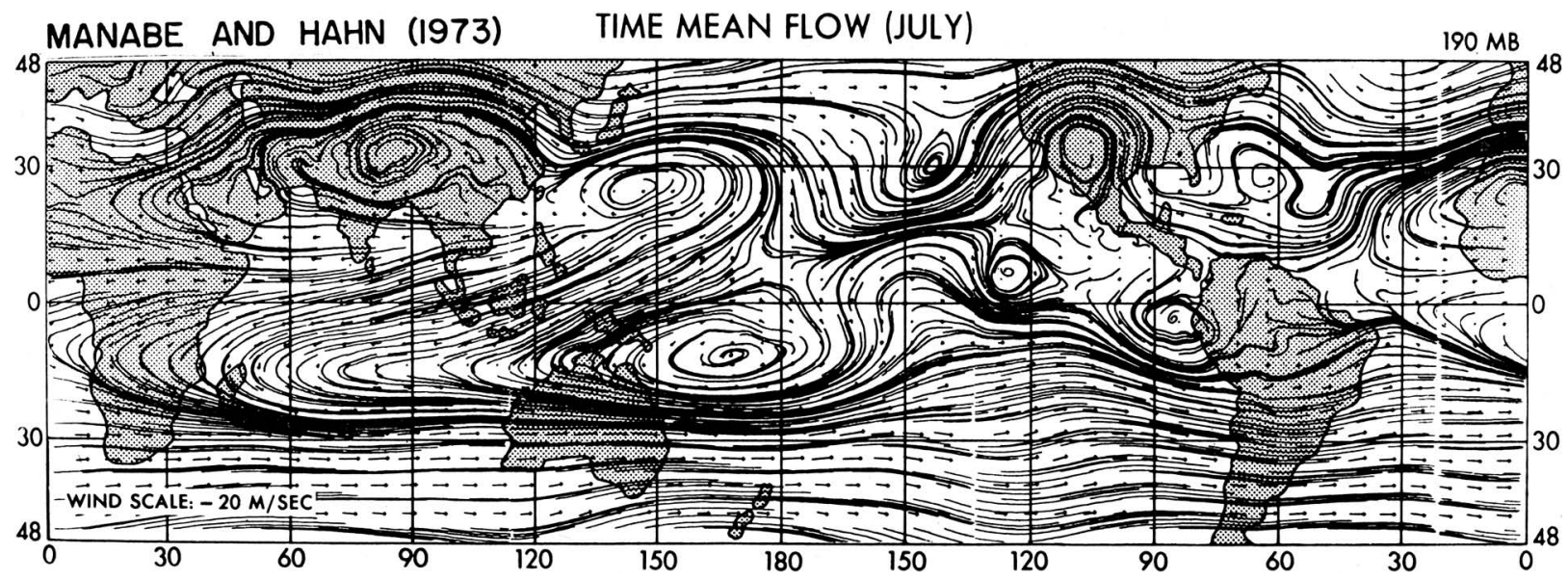

Fıc. 6. Manabe and Hahn's streamlines at $190 \mathrm{mb}$ surface for July mean conditions (Princeton general circulation experiment). The principal circulation $I$ features may be noted. 


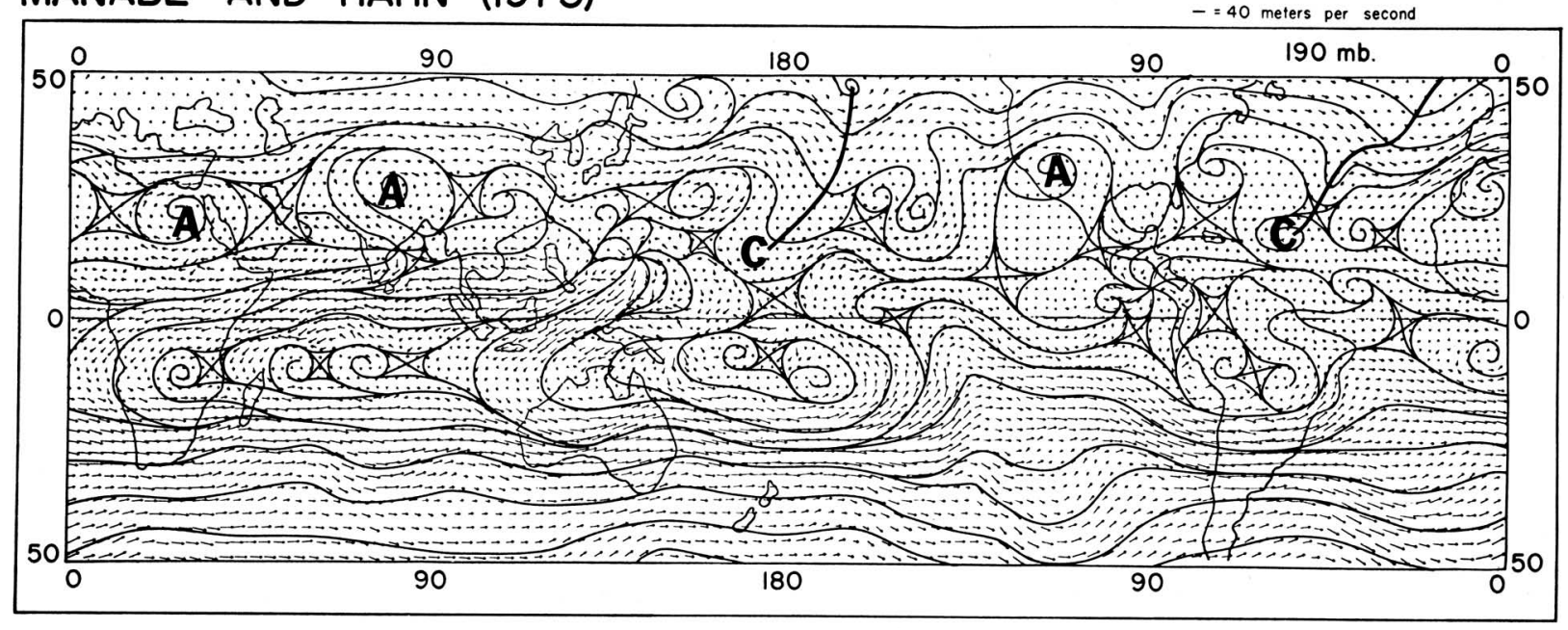

Fig. 7. Manabe and Hahn's streamlines at $190 \mathrm{mb}$ surface for a typical July day (Princeton general circulation model). The principal circulation $I$ features may be noted.

differentials due to the land-ocean contrasts. Abbott shows these results by carrying out long-term numerical integrations in a hemispheric general circulation experiment. The principal ingredients of his general circulation model are the following:

1) Quasi-geostrophic vorticity equation with friction.

2) Thermodynamic energy equation with a steady heating function that varies along $x, y$, and $p$.

A three-level hemispheric model is integrated with an equatorial ultralong wave steady flow as a boundary condition. This equatorial boundary condition provides for cross-equatorial flux of angular momentum from the winter hemisphere (Newell et al., 1969), which is one of the crucial elements in the experiment.

Abbott's principal results are the following:
1) Heating function generates eddy available potential energy on the scales of the steady differential heating.

2) Rising and sinking motions form over regions of heating and cooling, respectively.

3) As a consequence of (1) and (2) (warm air rising and relatively cooler air sinking) there is a generation of eddy kinetic energy on the scales of the steady heating functions.

4) Kinetic energy exchanges in the experiment are shown to be in close agreement with observational studies of Kanamitsu et al. (1972). The main results in this category for a tropical belt, are: Mean zonal flows receive kinetic energy from the long waves (wavenumbers 1 and 2) and give kinetic energy to shorter waves (especially around wavenum-

\section{ABBOTT (1973)}

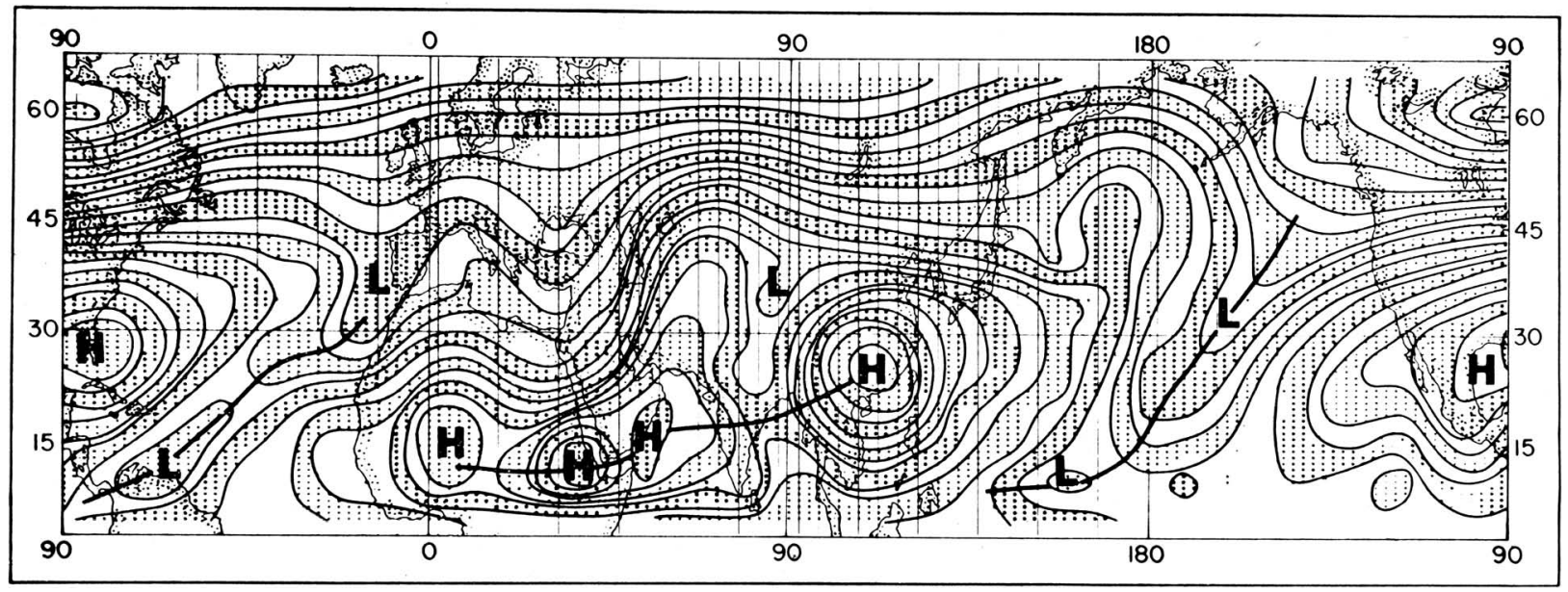

Fig. 8. Abbott's streamfunction at $200 \mathrm{mb}$ on day 30 for a quasi-geostrophic general circulation model. Streamfunction interval is $5 \times 10^{5} \mathrm{~m}^{2} \mathrm{sec}^{-1}$. 
ber 8). Planetary-scale waves are shown to be the major energy sources for the tropical general circulation, and barotropic energy exchanges via nonlinear "wave-wave" interactions act as important transfer mechanisms.

As regards simulation of the $200-\mathrm{mb}$ climatology, the principal circulation features, $I$, are found to be in very close agreement with observations. Abbott's streamfunction for day 30 for this experiment and a mean map averaged over 20 days for this run are shown in Figs. 8 and 9. The tilted mid-oceanic troughs are especially noteworthy in this experiment.

c) In this section, we feel that it is pertinent to review the results of a long-term general circulation experiment of Alyea (1972). This is a spectral two-level model. Our attention was drawn to this work because the July simulations of the 250-mb flows were surprisingly not in agreement with the major observed features such as the Tibetan high, mid-oceanic troughs, Mexican high and the easterly jet. The discrepancies between the results of his numerical general circulation model and his observations may be noted in Fig. 10. It is of interest to examine the total physics of this model, and to speculate on reasons for such major differences between observations and calculations in this study.

It should be noted, however, that Alyea's primary concern was not to verify the mean $250-\mathrm{mb}$ July simulations with present day mean 250-mb July observations. His interest was in a comparison of present day general circulations with a simulation of an ice age paleoclimate 18,000 years ago.

Some of Alyea's important model features are:

1) Two-level hemispheric quasi-geostrophic model, the two levels being the 250 - and 750 -mb surfaces.

2) Spectral formulation.
3) Orographic influences included as a lower boundary condition for the omega equation.

4) Air-sea interaction.

5) Short wave radiative heating as a function of latitude only.

6) Long wave radiative cooling (or heating) varies as a function of position and time over the land areas, ice covered areas, and in the atmosphere.

7) Convective adjustment is invoked (as a function of space and time) where large-scale convective instability is indicated during the prediction; this serves to provide a vertical redistribution and also an eastwest differential in the heat release.

There are many other details that enter into the workings of such a complicated physical-numerical model; we shall not discuss these here. Of interest here are reasons why large scale zonal asymmetries did not develop in Alyea's two-level hemispheric general circulation model as they did in Abbott's three-level counterpart.

We feel that there are at least two major differences in the physics of these two studies. The steady heating function in Abbott's study evidently is quite different from the computed time-dependent heating in Alyea's model. The intensity of the heating in Alyea's model was evidently too weak in the subtropics and thus could not maintain a blocking thermal high over the Asian highlands. Another major difference is in the boundary conditions at the equator. Observations during northern summer (Newell et al., 1969) show that there is a flux of westerly momentum towards the summer hemisphere and a flux of kinetic energy towards the winter hemisphere across the equator. Abbott accomplishes this at the equator by his choice of boundary conditions of a streamfunction based on the geometry of the observed ultralong waves at the equator.

\section{ABBOTT (1973)}

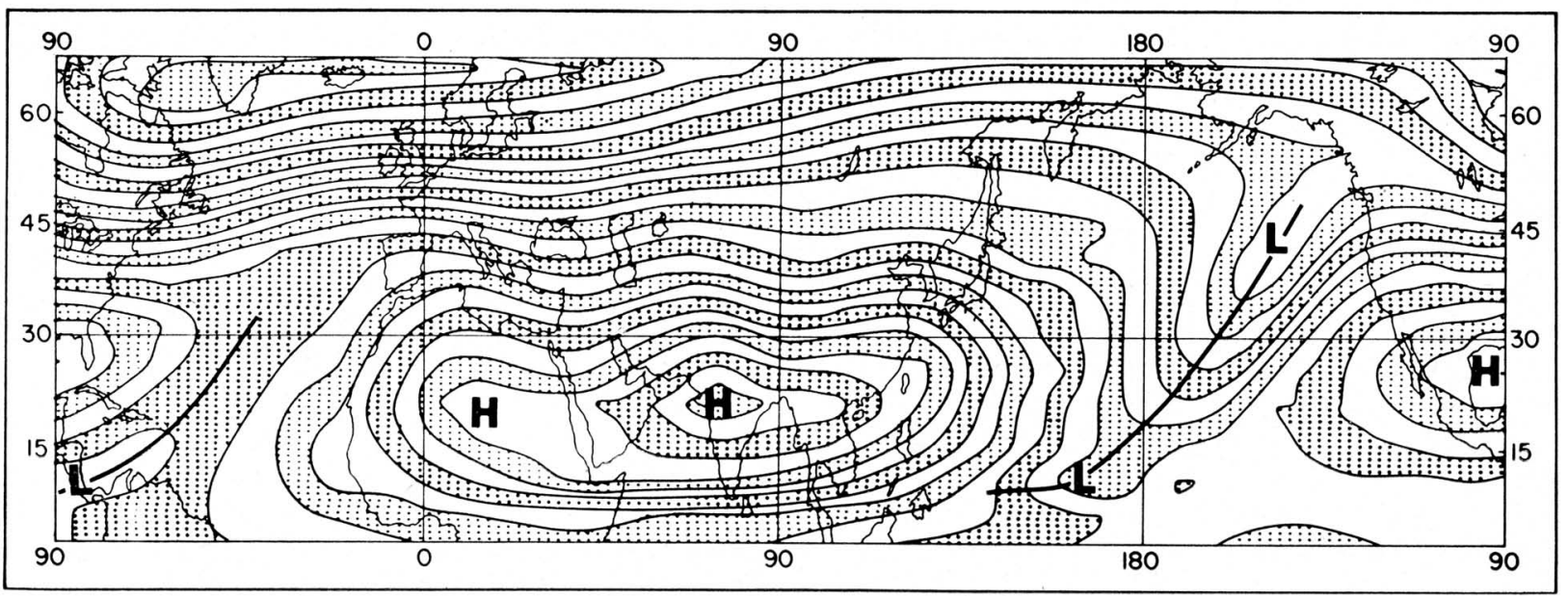

Fig. 9. Abbott's time averaged streamfunction between day 10 and day 30 for a quasi-geostrophic general circulation model. Streamfunction interval is $5 \times 10^{5} \mathrm{~m}^{2} \mathrm{sec}^{-1}$. 

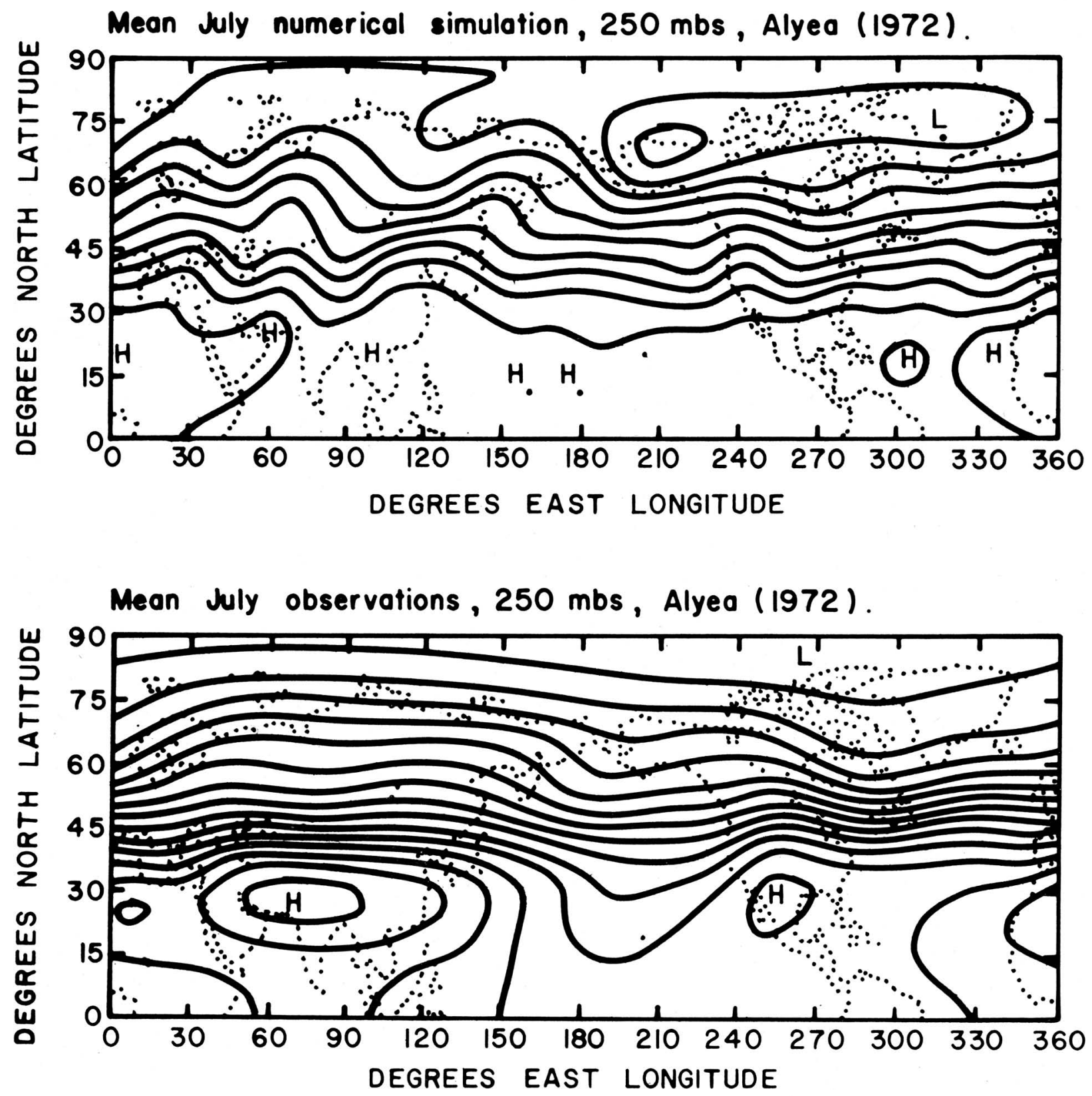

Fig. 10. Alyea's mean July heights. Contours from numerical simulation and observations at $250 \mathrm{mb}$. (Contour interval: top chart $6 \mathrm{dkm}$, bottom chart $3 \mathrm{dkm}$.)

d) Holton and Colton (1972) recently diagnosed the 200-mb vorticity field for Krishnamurti's (1971a, b) observed tropical and subtropical 1967 northern hemisphere summer circulations. They noted that the seasonal mean vorticity and divergence fields were almost exactly out of phase, the Tibetan and Mexican anticyclones nearly coincident with the centers of maximum divergence, and the mid-oceanic troughs nearly coincident with the centers of maximum convergence. They concluded that such a phase relationship precluded a balance between the production of vorticity by the divergence field and the horizontal advection of vorticity.
Such a balance, they reasoned, would have required a quarter wave phase shift between these two fields.

Using Krishnamurti's seasonal mean divergence field as a time-independent forcing function, they found that the observed seasonal mean vorticity and divergence fields at $200 \mathrm{mb}$ were mutually consistent only if the vorticity produced by the horizontal divergence field was dissipated on a time scale of about one or two days. This was accomplished in their linearized, diagnostic vorticity equation, by introducing a viscous drag term, where the rate of viscous drag was constant in time and space. 
Holton and Colton acknowledged that viscous dissipation of vorticity on a time scale of a day or two was unreasonably large since the time scale for large-scale vorticity mixing in the upper troposphere is usually considered to be of the order of weeks. Concentrating on the Tibetan plateau region, they hypothesized that the strong horizontal divergence at $200 \mathrm{mb}$ is primarily associated with cumulus outflow. Thus, they reasoned, the viscous drag term served to parameterize the vertical transport of cyclonic boundary layer vorticity by subgrid scale, deep cumulus convection which acted on a time scale of about two days and balanced the production of anticyclonic vorticity by the divergence field at $200 \mathrm{mb}$ over Tibet.

Similar balances have been suggested by Williams (1970) and Reed and Colton (1971) to account for large residuals computed for vorticity budgets in equatorial waves.

We should remark, however, that the question of the vorticity balance at $200 \mathrm{mb}$ in the mid-oceanic troughs has been neglected. Krishnamurti's data indicates that cyclonic vorticity production by planetary scale convergence in these regions is as vigorous as it is for anticyclonic vorticity production over the Tibetan plateau. However, unlike the southeast Asian region, which abounds with deep cumulus convection during the Indian monsoon season, the mid-oceanic regions are relatively void of organized deep convection. This fact precludes operation of the balancing mechanism, suggested by Holton and Colton, in the vicinity of the Tibetan high and leaves the problem of the $200-\mathrm{mb}$ vorticity budget in Northern Hemisphere summer open to further examination.

Colton (1973), utilizing some of the results of Holton and Colton's (1972) study, examines the effects of transient, synoptic-scale disturbances on the forced, large-scale monsoonal circulation at $200 \mathrm{mb}$ in the Northern Hemisphere summer. The governing equation for his onelevel semi-spectral model is the nonlinear vorticity equation including a viscous drag term applied only to the forced modes (wavenumbers 1, 2, and 3) and, as discussed by Holton and Colton (1972), is intended to control the amplitude and phase of these forced modes by crudely parameterizing vorticity transfer by deep cumulus convection. The stationary forcing function is Krishnamurti's (1971b) computed 200-mb seasonal mean divergence for wavenumbers 1-3. The free modes (wavenumbers 4-15) interact nonlinearly and barotropically with the externally forced modes.

Colton finds that short term nonlinear barotropic instabilities on the forced planetary scales cause synoptic transient disturbances in the mid-Pacific trough and along the easterly jet over the Indian ocean to develop and grow. He concludes that this barotropic nonlinear transfer of energy to synoptic scales of motion serves as an energy sink for the forced, quasi-stationary planetary waves in Northern Hemisphere summer.

In the light of other work in this area, several comments should be made. Colton's conclusion that transient synoptic scales of motion serve as an energy sink for the forced planetary scales agrees with the results of Abbott (1973). Abbott's model differs from Colton's in many important respects. Notably, Abbott's is multi-level and his planetary waves are forced by a space-dependent heating function. His climatology as well as his energetics are in very close agreement with observations. An exception, however, is that his divergence and vorticity fields are approximately one-quarter wavelength out of phase. This is an imposed and necessary condition in order to keep the forced planetary waves stationary. (An alternative would have been to follow Holton and Colton (1972) and introduce a viscous drag term.)

Colton's climatology differs somewhat from observations; this is shown in Fig. 11. Rather than use Holton and Colton's value for the viscous drag coefficientwhich, as they show, would have produced forced stationary planetary circulations in close agreement with observations-Colton uses a value six times smaller. This produces planetary waves which are roughly similar to observed climatology but of larger amplitude and of different phase. The Tibetan high and mid-Pacific trough are approximately $50^{\circ}$ and $30^{\circ}$, respectively, to the west of their observed positions and both are considerably more intense. Also the mid-Atlantic trough and Mexican high are virtually absent. Colton notes that the seasonal mean of the planetary scale features is considerably weaker than their daily values. Therefore to produce large scale vorticity gradients as strong as those observed

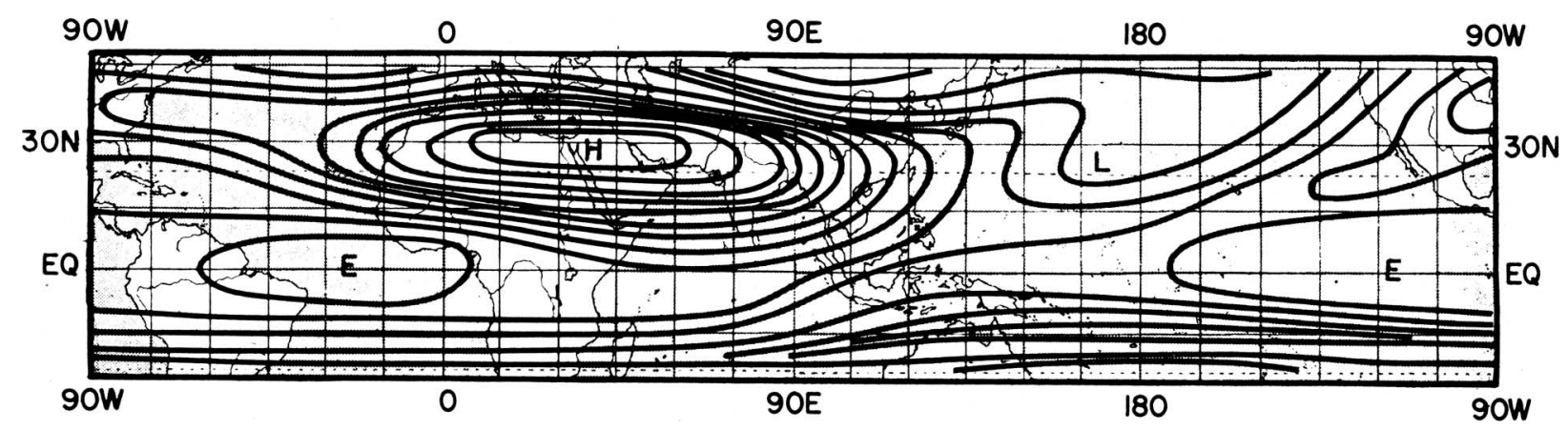

Fig. 11. Time averaged streamfunction from Colton (1973). Interval of analysis, $5 \times 10^{5} \mathrm{~m}^{2} \mathrm{sec}^{-1}$. 
by Krishnamurti on a day-to-day basis (and hence, to produce local barotropic instabilities) he uses a smaller damping coefficient. Unfortunately the planetary scale phase shift and the absence of western hemisphere features are by-products.

If, in fact, on a day-to-day basis, intense vorticity gradients on the planetary scales do produce short term local barotropic instabilities which serve as a sink mechanism for those forced scales, Abbott and Colton's results may provide at least a partial balancing mechanism for the large vorticity imbalances at $200 \mathrm{mb}$ in the Northern Hemisphere summer. For unlike Holton and Colton's balancing mechanism of deep cumulus convection, their nonlinear vorticity sink mechanism presents no special difficulties over the oceans. However, in order to satisfy other requirements, both Abbot and Colton produced vorticity and divergence fields, which, unlike those observed, are approximately one-quarter wavelength out of phase. Therefore, they, a priori, make nonlinear advection of vorticity an important part of the vorticity balance.

e) Webster (1972, 1973a, b) examines the mechanisms responsible for maintaining the stationary disturbances of the tropics by investigating the response of the tropical atmosphere first to local stationary forcing, and then to remote forcing with a two-layer linear, hydrostatic, primitive equation numerical model in spherical coordinates. Linear dissipation forms are used to parameterize the effects of surface friction, turbulent momentum exchanges in the vertical, and radiational cooling. Realistic basic currents are used as initial conditions.

Using the same model, Webster (1973b) examines the structure of the tropical disturbances generated in response to steady seasonal forcing. His local, steady forcing consists of 1) surface topography, and 2) spatial distribution of latent heat release. Both idealized and realistic spatial distributions of the forcing functions are considered. In this case no latitudinal limits are placed
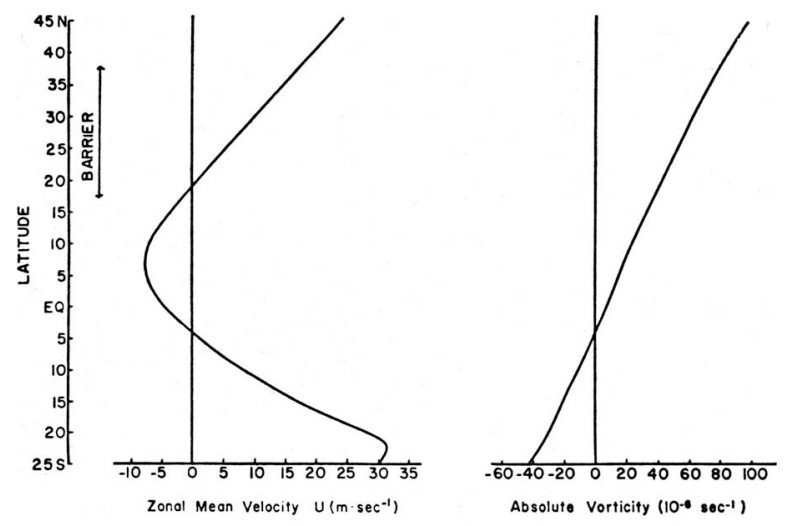

Fig. 12. Seasonal zonal average of the zonal velocity and absolute vorticity as a function of latitude at $200 \mathrm{mb}$ for June, July, August 1967. The latitudes where the barrier is placed are indicated on the top left. on the model, but the idealized forcing functions are assumed to decay exponentially poleward of latitude $30^{\circ}$.

For the remote forcing study, Webster (1973a) restricts his model region to a band bounded by latitude $40^{\circ}$, and specifies the remote forcing in terms of boundary conditions at these latitudes. His principal results are:

1) Dissipative effects close to the equator are very important.

2) Latent heating is the dominant forcing at low latitudes, but orography is important at higher latitudes where its effect is comparable to that of latent heating.

3) Local forcing is more important at low latitudes, but mid-latitude forcing dominates the subtropics.

4) The response near the equator is due to both local latent heating and steady forced motions at subtropical latitudes, and depends on both the basic state and magnitude of the forcing.

5) Low wavenumber forcing dominates the easterlies where the steady state structure is mainly trapped Kelvin waves. In mid latitudes the response is equally partitioned relative to wavenumber forcing and the structure is that of the Rossby wave.

\section{Tibetan high-a barrier for tropical zonal flows during northern summer}

We feel that the numerical simulation of the belt of anticyclones over the Asian highlands by a proper parameterization or specification of the heating function is a crucial element. Once the warm anticyclonic circulations form, they act as mechanical barriers and influence the climatology of the remaining tropical zonal belt. It is a purpose of this paper to indicate this latter aspect of the blocking high.

As stated in Section 1, our primary interest is to isolate some important mechanisms that are crucial for our understanding of the 200-mb northern summer climatology. In this section we shall discuss a simple numerical experiment in which the Tibetan high is treated as a mechanical barrier.

\section{a) Statement of the problem}

The problem we consider here is the following: We are seeking long-term solutions of the barotropic nondivergent vorticity equation,

$$
\frac{\partial}{\partial t} \nabla^{2} \psi=-J\left(\psi, \nabla^{2} \psi\right)-\beta \frac{\partial \psi}{\partial x},
$$

for the following given conditions:

1) An equatorial $\beta$ plane.

2) Initial state based on observed mean zonal flow for summer 1967 at $200 \mathrm{mb}$ as a function of latitude (Fig. 12).

3) Walls at $45 \mathrm{~N}$ and $25 \mathrm{~S}$ where a prescribed streamfunction, $\psi$, is independent of $x$ and $t$, its value 
adjusted from Fig. 12 to satisfy the relation

$$
-\int_{y_{1}}^{y_{2}} \frac{\partial \psi}{\partial y} d y=\int_{y_{1}}^{y_{2}} u d y
$$

or

$$
\psi\left(y_{1}\right)-\psi\left(y_{2}\right)=U\left(y_{2}-y_{1}\right)
$$

where $U$ is mean zonal flow in the belt $25 \mathrm{~S}$ and $45 \mathrm{~N}$. One of these boundary values of the streamfunction can be assumed to be equal to zero without any loss of generality.

If we assume $\psi\left(y_{2}\right)=0$, then at the southern boundary the value of the streamfunction is determined from initial observations of $u$. Initial streamfunction in the interior of the domain is given by

$$
\psi(y)=\psi\left(y_{1}\right)-\int_{y_{1}}^{y} u d y .
$$

4) An internal boundary defined by a fixed barrier $\psi_{B}=$ constant is taken from the observations of Krishnamurti (1971b).

The geometry of the initial state, as defined from (1) through (4) above, is portrayed in Fig. 13. The internal barrier is impulsively introduced in the straight zonal flow. The reader is referred to Krishnamurti (1971b) where a time mean streamfunction for the summer season is shown. The size and shape of the barrier is selected from this study.

In summary, the problem we consider may be stated as a study of the evolution of statistically stationary flows past a barrier from initial zonal flows in a bounded beta plane.

\section{b) Numerical calculation methods}

The Arakawa (1966) advection scheme, a five-point second-order Laplacian, sequential or Leibmann relaxation method, and iterative Euler-backward time differencing scheme constitute the numerical methods used in this study. The details are not given here, but the reader may refer to a standard text (e.g., Haltiner, 1971), where most of the details can be found.

A latitude-longitude mesh $2.5^{\circ}$ by $2.5^{\circ}$ is used. This constitutes 144 grid points along the latitude circle. The domain in the south-north direction extends between $25 \mathrm{~S}$ and $45 \mathrm{~N}$, i.e., 29 grid points. The fixed value of the streamfunction at $45 \mathrm{~N}$ is zero; at $25 \mathrm{~S}$ its value is taken to be $5.25 \times 10^{8} \mathrm{~m}^{2} \mathrm{sec}^{-1}$.

A fixed value of $4.75 \times 10^{8} \mathrm{~m}^{2} \mathrm{sec}^{-1}$ is assumed around the barrier. These values are, as stated earlier, based on observations.

\section{c) Boundary conditions at the barrier}

The procedure adopted here is essentially similar to that used by Fromm (1963). In Fromm's study he considered the problem of non-steady incompressible viscous fluid flows past obstacles. Fromm's work deals with successful numerical integration for various ranges of values of Reynolds number; his results were in essential agreement with experimental work on the evolution of the Karman vortex street. Although the inclusion of beta effect and a lack of explicit viscous terms makes our numerical experiment very different from Fromm's work from a physical point of view, there are many similarities in the two with respect to computational procedures and treatment of the boundary condition at the barrier. Fromm uses a finite difference scheme for the advective terms that conserves domain mean square vorticity but not the mean kinetic energy. We have used Arakawa's (1966) scheme which conserves both of these properties.

In the treatment of the obstacle we must first assure that the periphery of the obstacle is a streamline of the flow. This means $\psi$ must be kept fixed during any numerical integration procedure. Another important constraint is that there be no loss or gain of vorticity as a consequence of transports at the wall. We first replace

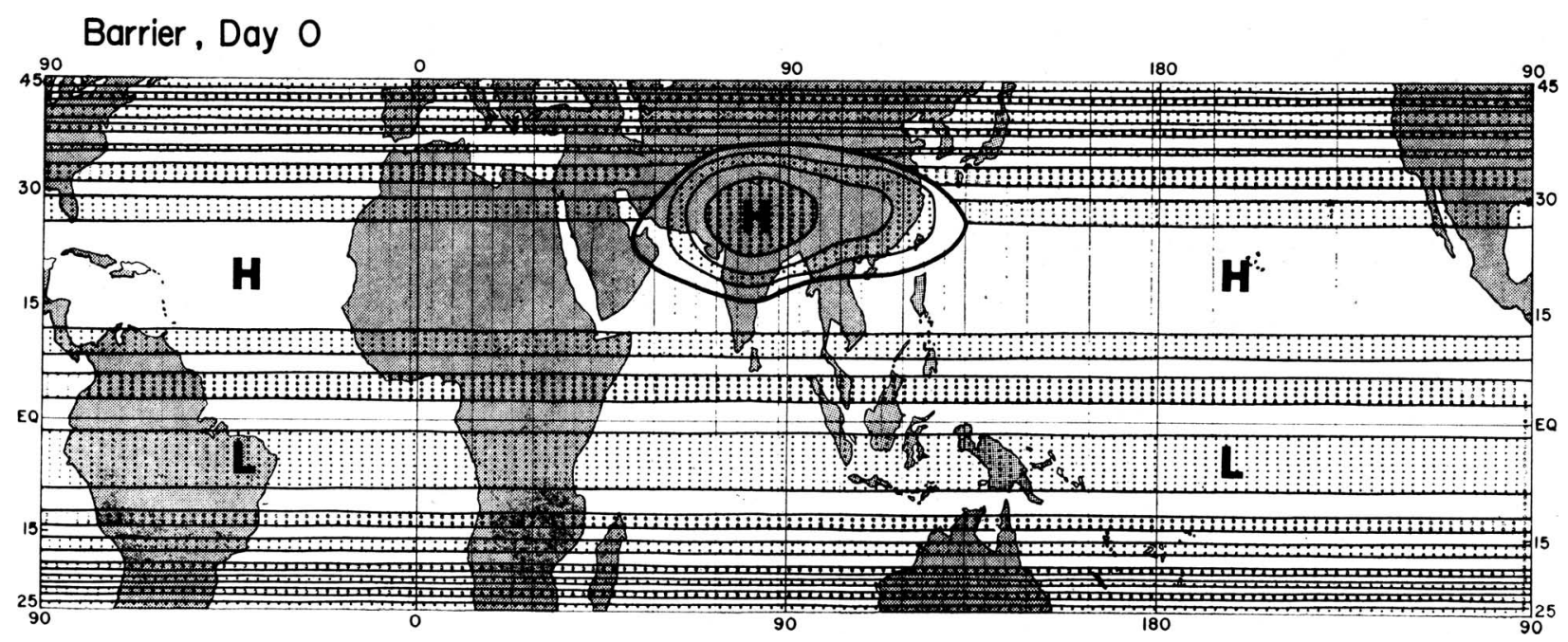

Fig. 13. Streamfunction on day 0 (including the impulsively introduced barrier). Interval is $5 \times 10^{5} \mathrm{~m}^{2} \mathrm{sec}^{-1}$. 


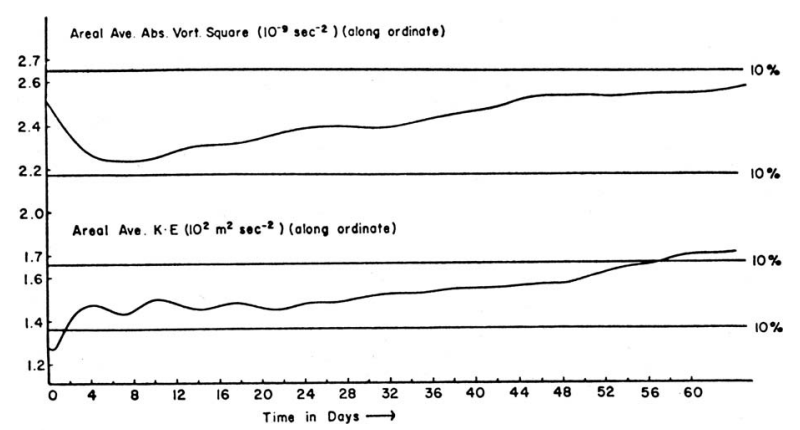

FIG. 14. Mean square vorticity and mean kinetic energy plotted as a function of time for the barrier experiment. The period between day 0 and day 4 is regarded as an adjustment period.

the semielliptical shape of the obstacle by a number of line segments connecting grid points; the connections are carried out either by small segments along the $x$ axis or $y$ axis, the segments however do not connect diagonally across a grid square. The streamfunction and vorticity are kept fixed and equal to the climatological mean value at this boundary.

As in Fromm's study, we advance time at all points of the fluid except those at the obstacle. Thus the second order Arakawa advection is easy to evaluate at all points
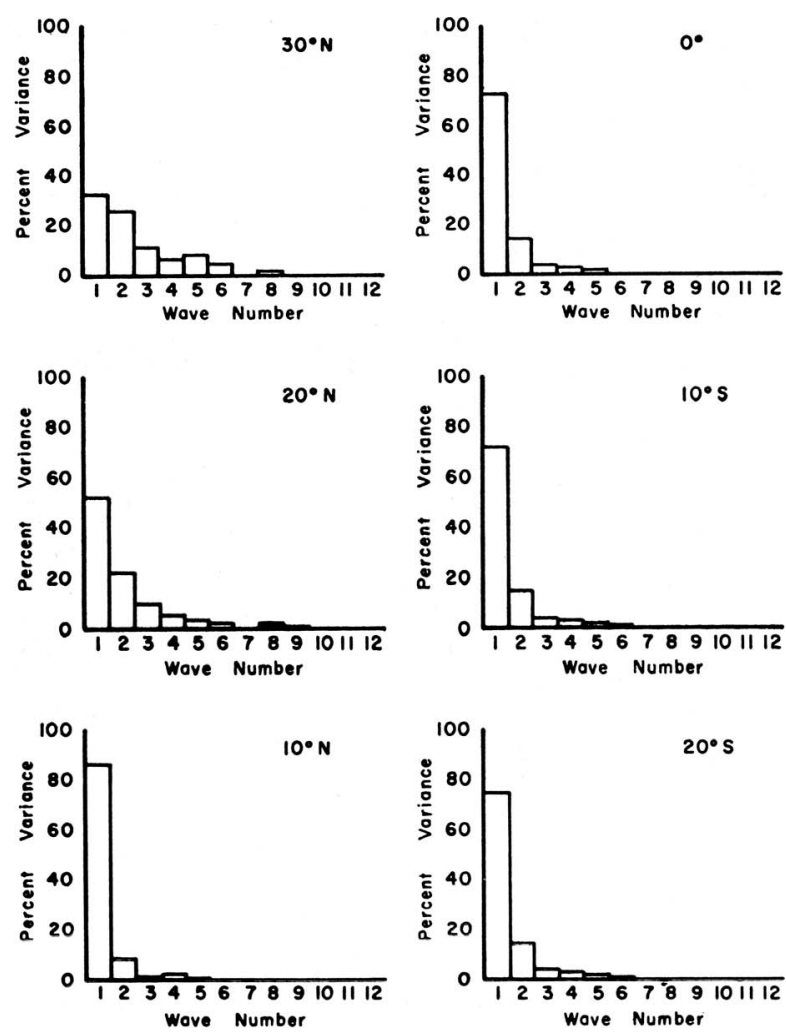

Fig. 15. Percent variance as a function of zonal wavenumber from spectral analysis (of the transient part of the streamfunction) along latitude circles. Results computed from daily values of streamfunction and averaged from day. 20 to day 50. away from the obstacle. And furthermore, since the normal flow at the boundary is zero, there is no flux of vorticity at the boundary.

For purposes of calculation of integrals around latitude circles we shall, later in this paper, assume that inside the barrier there exists a steady flow. The isopleths of this steady flow are shown in Fig. 13; this is based on time mean flow from observations at $200 \mathrm{mb}$. It should, however, be noted that we do not use the region inside the barrier for the numerical integration of flows around the barrier. Our two boundary conditions at the barrier, i.e., $\psi=$ constant along the barrier and $\Delta^{2} \psi$ independent of time and given by time mean observations, are however consistent with an assumption of such a steady mean flow inside the barrier. This assumption of a steady flow allows us to evaluate energy exchanges between harmonic wave components.

\section{d) Generation of transient motions}

Fig. 12 indicates the north-south profile of the mean zonal flow and of the absolute vorticity. This is based on the mean data for three months June, July, and August 1967. The mean zonal flow is easterly everywhere between roughly $17 \mathrm{~N}$ and $5 \mathrm{~S}$ and is westerly elsewhere. Note that the barrier extends between roughly $17 \mathrm{~N}$ and $38 \mathrm{~N}$. The absolute vorticity profile of the initial state shows quite clearly that the zonal flow profile would be barotropically stable in the sense of the Kuo (1949) criteria. However, the presence of an impulsively introduced barrier in this zonal flow profile is another story. The domain we consider is closed and there is no flux of vorticity or mass from the boundaries. Invariance of mean square vorticity and mean kinetic energy is provided by the use of conservative finite difference analogs for the nonlinear advective terms. Because of the impulsive addition of the barrier, the first 4 days of the forecast period is regarded as an adjustment time. Both of the quadratic invariants are found to be conserved within $5 \%$ between 10 and 60 days (Fig. 14).

Exact invariance is not possible for several reasons, such as slight errors due to the time differencing scheme, round off and truncation errors in the linear terms (the beta term), and the impulsive start of the problem.

Transient wave motions form both in the northern and southern hemisphere. North and south of the barrier the initial flows carry $100 \%$ of the total variance of the motion field in the zonal direction, i.e., in wavenumber 0 . As time proceeds standing eddies and a statistically steady transient spectral distribution evolves. It should be noted here that the variance is evaluated from the streamfunction along a selected latitude circle. For this calculation at those latitude circles where the barrier is located note our discussion of the region inside the barrier in Section 3c. Results of 30-day averages (day 20 to day 50) for the percent variance of the streamfunction at selected latitude circles as a function of zonal wave number are presented in Fig. 15. It is quite clear that transient motions evolve in both the Northern and the Southern Hemisphere. 


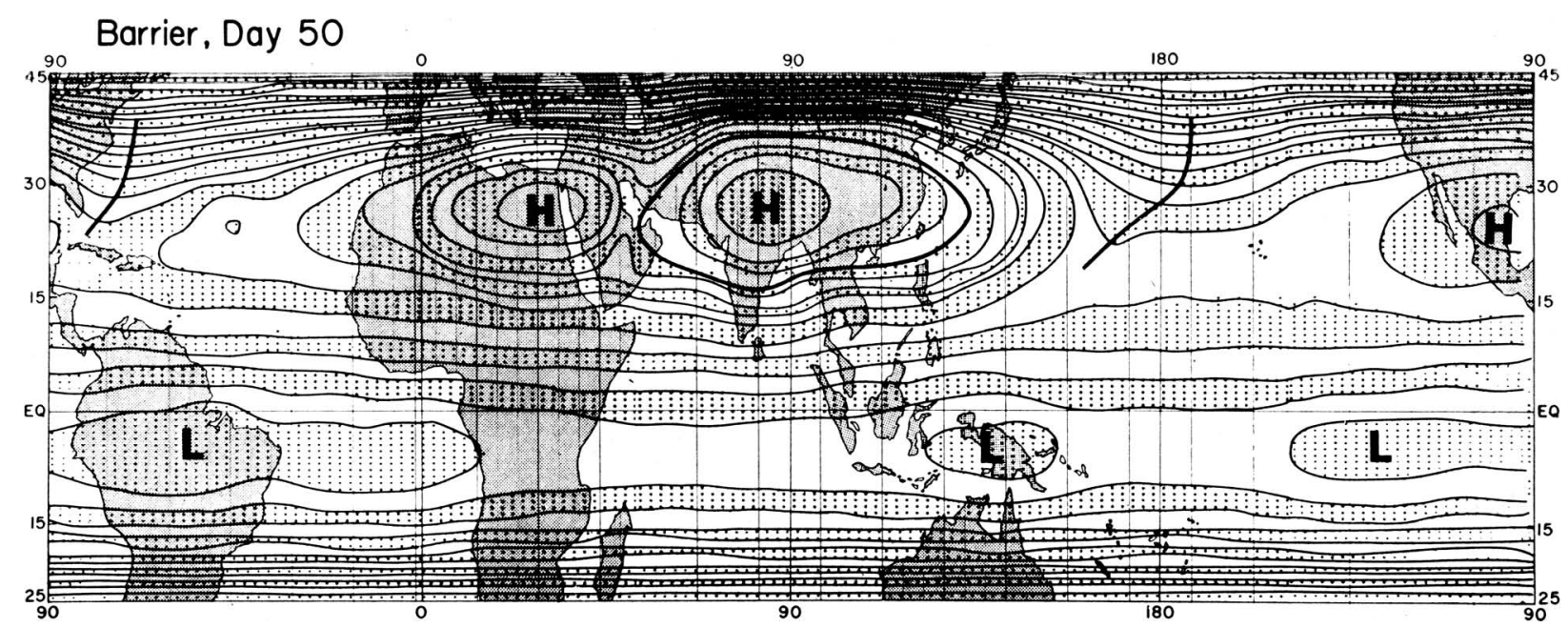

FIG. 16. Streamfunction $\psi$ on day 50 for the barrier experiment. Heavy line over Asia marks the outline of the barrier. Midoceanic troughs and principal anticyclones $H$, are indicated. Interval for $\psi$ is $5 \times 10^{5} \mathrm{~m}^{2} \mathrm{sec}^{-1}$.

We note that the amplitudes of the transient motions are large compared to that of the stationary (30-day mean) motions during the initial 20 days, thereafter their amplitudes are relatively smaller. This relates to the fact that in this experiment we note a slow relaxation time during which stationary patterns evolve due to the interactions of the transients with the barrier and with each other. Nonlinear interactions among waves are found to be large throughout the experiment; this is discussed elsewhere in this paper.

\section{e) Stationary fields}

Fig. 16 shows the streamfunction of day 50; the mean map between days 20 to 50 is shown in Fig. 17. Most of the circulation features on the mean map (Fig. 17) are easy to identify, i.e., Mexican high, mid-Atlantic trough,
mid-Pacific trough, African high, tropical easterly jet. The map on day 50 (Fig. 16) is also quite similar to the mean map. We have shown that the computed stationary fields are in essential agreement with the observations of the tropical 200-mb belt (Fig. 1). The features form as a result of interactions of a mean zonal flow with a barrier over the Tibetan region. The shape of the barrier, the profile of the initial zonal flow and the value of beta are the only initially prescribed three parameters that determine the climatology illustrated in Fig. 17.

A calculation of percent variance of the streamfunction as a function of zonal wavenumber for the 30-day mean motion field is shown in Fig. 18. At the equator and north of it, wavenumbers 1,2 and 3 carry most of the variance while south of the equator most of the vari-

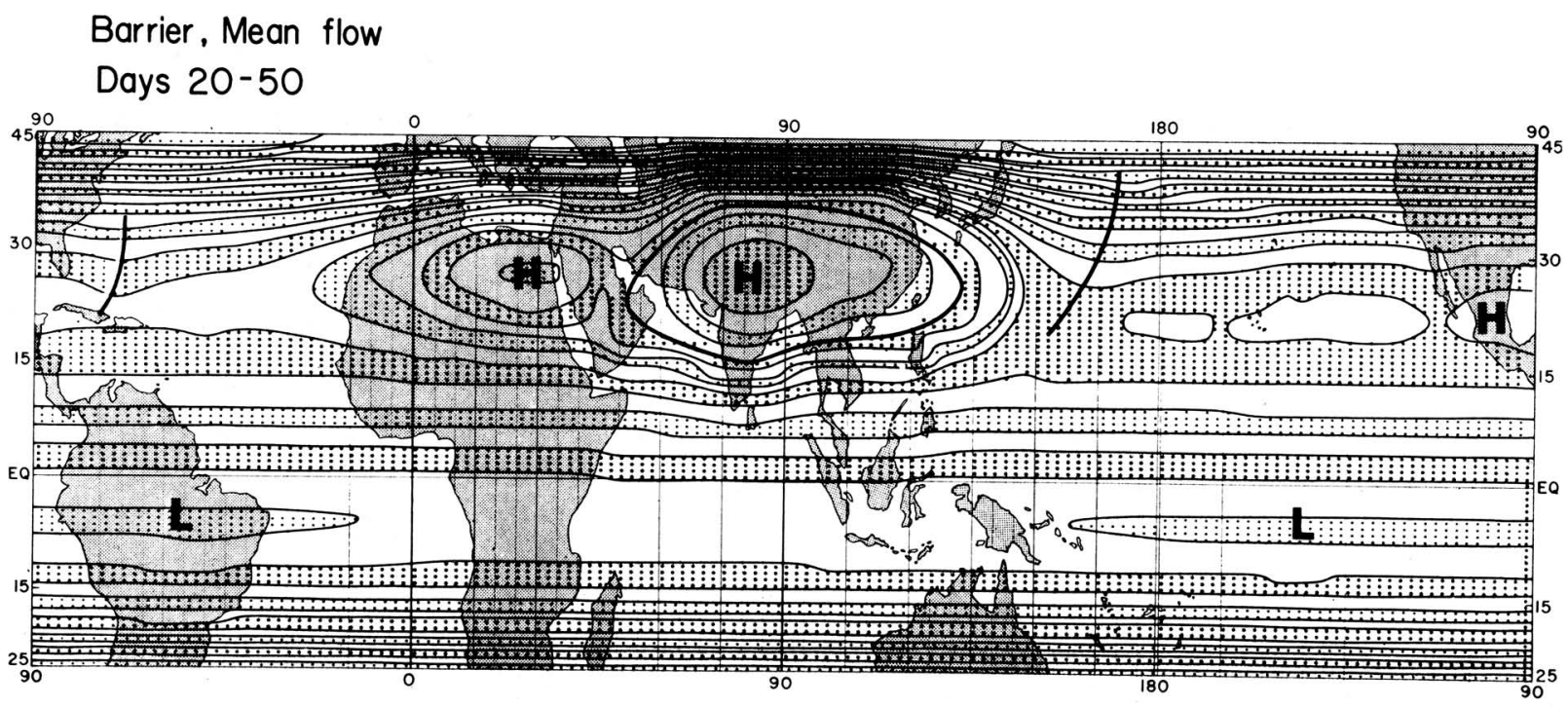

FiG. 17. Mean streamfunction $\psi$ days 20 to 50 for barrier experiment. Heavy line over Asia marks the outline of the barrier. Mid-oceanic troughs and principal anticyclones, $H$, are indicated. Interval of $\psi$ is $5 \times 10^{5} \mathrm{~m}^{2} \mathrm{sec}^{-1}$. 

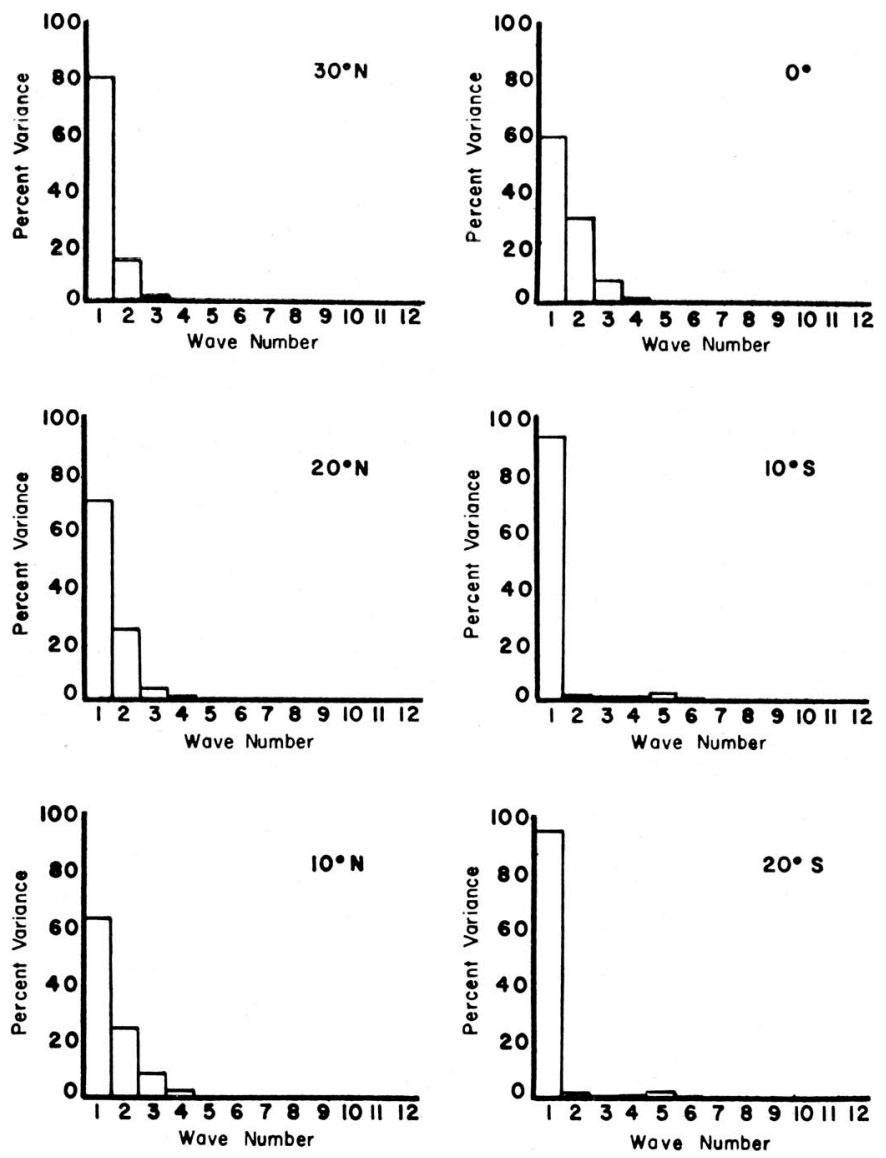

Fic. 18. Percent variation as a function of zonal wavenumber from spectral analysis (of the time mean streamfunction) along latitude circles. Motion field was averaged from day 20 to day 50 .

ance is in wavenumber 1 . Wavenumbers 1,2 , and 3 , north of equator describe the climatological features in the mean motion field.

f) On the maintenance of the mean motion field.

In this section we present a comparison of results of three sets of calculations addressed to the question of the maintenance of circulation features $I$ based on:

1) Observations at $200 \mathrm{mb}$ for June, July, and August 1967 (Kanamitsu et al., 1972).

2) Abbott's (1973) multi-level quasi-geostrophic hemispheric general circulation model.

3) The present experiment on the influence of the Tibetan high as a barrier.

The specific questions asked concern the energy sources and sinks for the long waves. The calculation procedure, following Saltzman (1970), is described by Kanamitsu et al. and Abbott in their respective studies.

For this comparison we shall define wavenumber 1 and 2 as long waves, wavenumbers 3 through 15 as short waves. We have calculated kinetic energy exchanges at one level (i.e., $200 \mathrm{mb}$ ) to examine the following ex- changes in a tropical belt:

$$
\begin{aligned}
& \text { short (S) } \leftrightarrow \text { Long (L) } \\
& \text { short (S) } \leftrightarrow \text { Zonal (Z) } \\
& \text { zonal (Z) } \leftrightarrow \text { Long (L) }
\end{aligned}
$$

The tropical belt considered is $30^{\circ}$ latitude wide in the north-south direction.

Barotropic exchanges result in a loss or gain of eddy kinetic energy on a certain scale (wavenumber $n$ ) in the tropical belt. We may, following Saltzman (1970), express this grossly by the relation

$$
\begin{aligned}
\frac{\partial K_{n}}{\partial t}= & \text { "wave-zonal" exchanges, } \\
& + \text { "wave-wave" exchanges, } \\
& + \text { boundary fluxes of eddy kinetic energy, } \\
& + \text { boundary fluxes of eddy potential energy and } \\
& \text { pressure work at the boundaries. }
\end{aligned}
$$

Of these we shall be interested in a comparison of the first two items on the right hand side of the above for the three sets of calculations. 


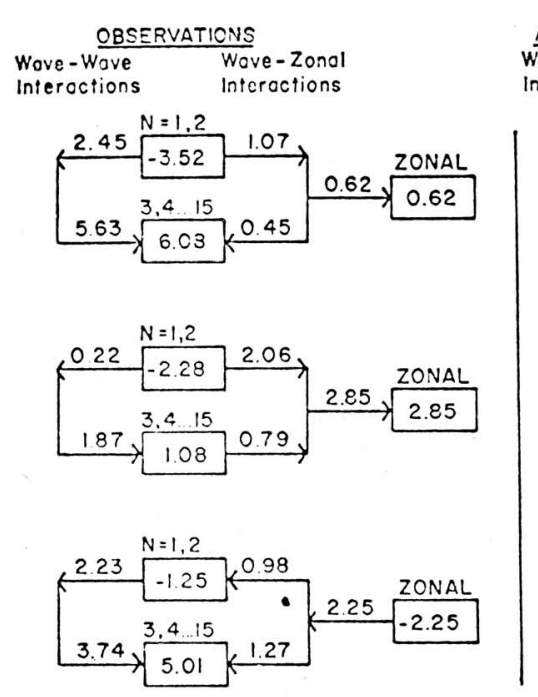

(a)

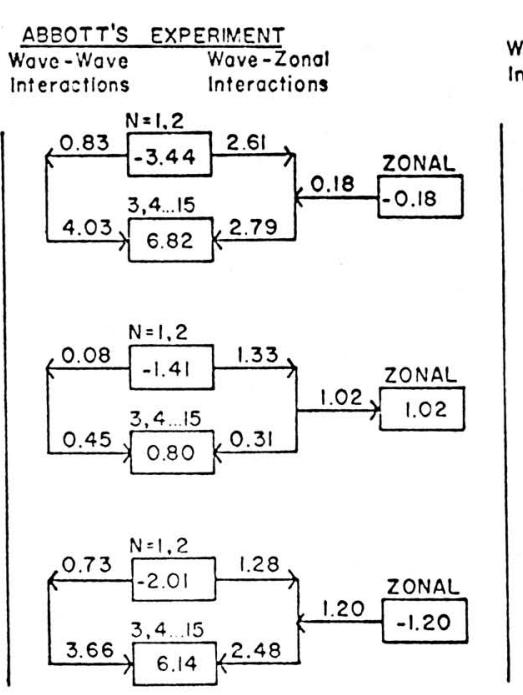

(b)

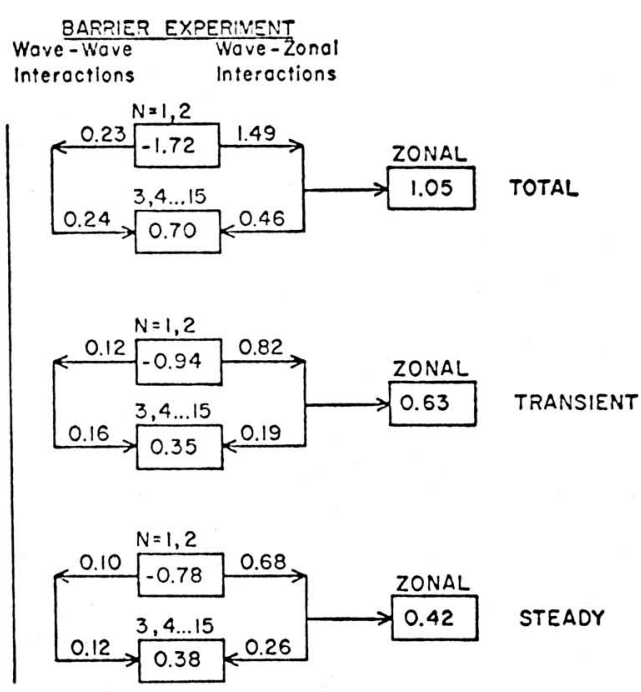

(c)

Fig. 19. Kinetic energy exchanges between long waves, short waves and zonal flows for three different sets of calculations. Units are $\times 10^{-5} \mathrm{~m}^{2} \mathrm{sec}^{-3}$. The exchanges are subdivided into exchanges by the steady part of the motion field and by the transients.

\section{1) Observational energy exchanges}

These exchanges are grouped into the three categories, $S, L$, and $Z$. Results based on observations of Kanamitsu et al. (1972) for northern summer for the first 15 wavenumbers are summarized in Fig. 19a. We note an exchange for the long waves to both the zonal flows and to shorter waves. The results are for 92 days during summer of 1967. The units of the energy exchanges are $10^{-5}$ $\mathrm{m}^{2} \mathrm{sec}^{-3}$.

A pronounced persistent tilt of long waves from southwest to northeast results in a large flux of westerly momentum away from the tropics; this results in a strengthening of the tropical zonal easterlies. This is explained as the mechanism for the transfer $K_{L} \rightarrow K_{\mathrm{z}}$. The exchange $K_{z} \rightarrow K_{S}$ is somewhat harder to interpret. The northsouth profile of the observed mean zonal flow is barotropically stable in the linear sense (Fig. 12), hence this exchange of kinetic energy between the zonal flows and shorter waves would have to be interpreted as nonlinear barotropic energy transfers in time dependent flows that evolve. Fig. 19a also indicates a significant "wavewave exchange" from longer to shorter waves. All of this suggests that there has to be a significant energy source for the long waves.

\section{2) Abbott's exchanges with steady east-west heating}

Abbott's (1973) calculations of corresponding energy exchanges are shown in Fig. 19b. There is a close agreement between Fig. 19a and Fig. 19b thus indicating the importance of the east-west heating in providing the needed energy source for the long waves. We shall not go any further into Abbott's work here since his results are being published in detail elsewhere.

\section{3) Energy exchanges for the barrier experiment}

The treatment of the region inside the barrier is discussed in Section 3c. Fig. 19c shows the results of energy exchanges between day 20 and day 50 for the barrier experiment. Again the gross direction of the energy exchanges is in essential agreement with observations. The presence of a barrier in this model does simulate an energy source for the long waves. This energy is transferred barotropically to the zonal flows and to the shorter waves.

In this experiment, pressure-work across the boundaries of the barrier acts as a source of energy for the long waves and a sink for the zonal flows and the shorter waves. Although we have simulated an energy source for the long waves via the use of the barrier, the mechanism is different from Abbott's specification of the steady heating. We should, however, recognize that the mean climatology simulated by the barrier experiment is not as realistic as in Abbott's study. The barrier experiment has merely illustrated the importance of the mechanical forcing of a blocking high for tropical general circulation.

\section{Concluding remarks}

We have demonstrated, via the use of a simple numerical experiment, the importance of the Tibetan high for the northern summer upper-tropospheric circulations over the tropics.

Although the Tibetan high exhibits many oscillations in its intensity, its influence on the zonal flows in the tropics can be modelled as a simple barrier. By specifying the profile of the mean zonal flows at $200 \mathrm{mb}$, the shape of the blocking high, a beta plane, and the prin- 
ciple of conservation of vorticity, we have obtained time mean motions similar to the observed climatology.

This study brings out an important distinction between thermal and dynamic anticyclones. Wexler (1951) presented a comprehensive review of these two types of anticyclones. Tropical upper-tropospheric circulations reveal many anticyclonic circulations on many different scales. Some of these are the upper structures of westward propagating meso-convective and easterly wave type lower tropospheric disturbances and tropical storms. This type of anticyclone, whose scale is of the order of a few thousands of kilometers, may be classed as thermal anticyclones. There are two well known quasi-stationary antciyclones that are associated with considerable convective activity; these are the Tibetan high and the anticyclonic circulation northeast of Australia. There are also a number of other quasi-stationary anticyclones, e.g., the Mexican high, the African high, the high northwest of Australia (see Fig. 1). We feel that these latter are dynamic anticyclones that form as a consequence of the blocking influence of the thermal highs on mean zonal flows. By placing a barrier on the location of the thermal Tibetan high we have demonstrated a mechanism for the formation of the African and the Mexican high over the northern summer tropics. The circulation features over the Southern Hemisphere were not quite properly simulated (see Fig. 16 and Fig. 1). A reason for this failure, we feel, is due to the fact that a large thermal anticyclone such as the one northeast of Australia cannot be simulated by a purely dynamical forcing. We feel that if we had blocked off both of these large quasi-stationary thermal anticyclones (Tibetan and northeast Australian) then we might have realized much better agreement with Fig. 1 over the Southern as well as the Northern Hemisphere. This would be a very worthwhile extension of the present work, because such a study might point out the importance of the southwest monsoons and of the intense rainfall systems over the Solomon Islands and New Hebrides on the entire tropical upper-tropospheric circulation. The importance of this latter region for tropical dynamics should be recognized since an examination of mean maps at 200 mb (Atkinson, 1971) reveal that persistent large upper anticyclones exist from April through October in this part of the world.

Another possible extension of this work would be in the use of pulsating barriers in simple experiments. We might impose a time oscillation of the Tibetan high with a frequency or sum of frequencies as suggested by observations (Fig. 4). In such an experiment the nature of transients and standing eddies might be somewhat different from the results obtained for a fixed barrier. Other simple extensions could incorporate in the dynamics the principle of conservation of potential vorticity instead of absolute vorticity. This can be done via use of a single-variable invariant as shown by Charney and Stern (1962). Any further additions to the physics may be unrewarding from the point of view of sim- plicity, and one might as well, in that case, analyze the results of a multi-level general circulation model.

In closing we may refer to the present GARP philosophy in the studies of monsoons. The Joint Organizing Committee (JOC) of GARP held a study group on the Monsoon experiment (MONEX) at Yeravan, U.S.S.R., during March 1973. This major observational experiment is scheduled for 1977. The planning of the observational phase of this program is presently being undertaken by JOC. The entire planning emphasizes interrelationships between monsoons and the global general circulations. It is evident from this study that the monsoon region does have a strong influence in the zonal and meridional directions around the globe.

Acknowledgments. We wish to convey our thanks to Dr. Douglas A. Abbott for providing us with some of the results of his experiment discussed in this paper.

This work was supported by the Atmospheric Science Section of the National Science Foundation under Grant No. GA-17822 and by the Department of Defense Contract No. 0769C0062. Computational support was provided by the National Center for Atmospheric Research (which is sponsored by the National Science Foundation), and by the Florida State University's Computing Center.

\section{References}

Abbott, D. A., 1973: Scale interactions of forced quasi-stationary planetary waves at low latitudes. Rept. 73-2, Dept. of Meteorology, Florida State University, Tallahassee, 190 pp.

Alyea, F. N., 1972: Numerical simulation of an ice age paleoclimate. Atmos. Sci. Paper No. 193, Dept. Atmos. Sci., Colorado State University, Fort Collins, Colo., $120 \mathrm{pp}$.

Arakawa, A., 1966: Computational design for long term numerical integration of fluid motion. Computational Physics, 1, 119-143.

Atkinson, G. D., 1971: Forecasters guide to tropical meteorology. Tech. Rept. No. 240, Air Weather Service (MAC), Scott Air Force Base, Ill., 360 pp.

Charney, J. G., and M. E. Stern, 1962: On the stability of internal baroclinic jets in a rotating atmsphere. J. Atmos. Sci., 19, 159-172.

Colton, D. E., 1973: Barotropic scale interactions in the tropical upper troposphere during the Northern summer. Unpublished manuscript, Dept. of Atmos. Sci., University of Washington, Seattle, Wash., 43 pp.

Fromm, J. E., 1963: A method for computing nonsteady, incompressible viscous fluid flows. Rept. No. LA-2910, Los Alamos Scientific Laboratory of the Univ. of California, Los Alamos, New Mex., 147 pp.

Haltiner, G. J., 1971: Numerical Weather Prediction. New York, John Wiley and Sons, Inc., $317 \mathrm{pp}$.

Holton, J. R., and D. E. Colton, 1972: A diagnostic study of the vorticity balance at $200 \mathrm{mb}$ in the tropics during the Northern summer. J. Atmos. Sci., 28, 1124-1128.

Kanamitsu, M., T. N. Krishnamurti, and C. Depradine, 1972: On scale interaction in the tropics during northern summer. J. Atmos. Sci., 29, 698-706.

Krishnamurti, T. N., 1971a: Observational study of tropical 
upper tropospheric motion field during northern hemisphere summer. J. Appl. Meteor., 10, 1066-1096.

, 1971b: Tropical east-west circulations during the northern summer. J. Atmos. Sci., 28, 1342-1347.

—, M. Kanamitsu, W. J. Koss, and J. D. Lee, 1973: Tropical east-west circulations during the northern winter. $J$. Atmos. Sci., 30, 780-787.

_ July, August 1971. Rept. No. 70-2, Dept. of Meteorology, Florida State Univ., Tallahassee, Fla., 114 pp.

Kuo, H. L., 1949: Dynamic instability of two dimensional non-divergent flow in a barotropic atmosphere. J. Meteor., 6, 105-122.

Manabe, S., and D. C. Hahn, 1973: The general circulation of the tropics as simulated by the time integration of a global model of the atmosphere with an annual cycle of solar radiation. (To be published.)

—, J. L. Holloway, Jr., and H. M. Stone, 1970a: Tropical circulation in a time integration of a global model of the atmosphere. J. Atmos. Sci., 27, 580-613.

- J. J. Smagorinsky, J. L. Holloway, Jr., and H. M. Stone, 1970b: Simulated climatology of general circulation model with hydrologic cycle: III. Effects of increased horizontal computational resolution. Mon. Wea. Rev., 98, 175-212.
Newell, R. E., D. G. Vincent, T. G. Dopplick, D. Ferruzza, and J. W. Kidson, 1969: The energy balance of the global atmosphere. The Global Circulation of the Atmosphere, G. A. Corby, Ed., Royal Meteorological Society, 42-90.

Reed, R. J., and D. E. Colton, 1971: Properties of synoptic scale wave disturbances in the equatorial western Pacific: Vorticity budget. Paper presented at the Seventh Technical Conference on Hurricanes and Tropical Meteorology. Abstract published in Bull. Amer. Meteor. Soc., 52, 767.

Saltzman, B., 1970: Large Scale Atmospheric energetics in the wave number domain. Rev. Geophys., 8, 289-302.

Webster, P. J., 1972: Response of the tropical atmosphere to local, steady forcing. Mon. Wea. Rev., 100, 518-541.

- 1973a: Remote forcing of time independent tropical atmosphere. Mon. Wea. Rev., 101, 58-68.

$\longrightarrow$, 1973b: Temporal variation of low-latitude zonal circulations. Unpublished manuscript.

Wexler, H., 1951: Anticyclones. Compendium of Meteorology, American Meteorological Society, Boston, 621-630.

Williams, K. T., 1970: A statistical analysis of satellite-observed trade wind cloud clusters in the western North Pacific. Rept. No. 161, Dept. of Atmospheric Science, Colorado State University, Fort Collins, 1-80. 


\section{-ACOUSTIC SOUNDER-}

available from Science Assoc., Inc. • manufactured by AeroVironment Inc.

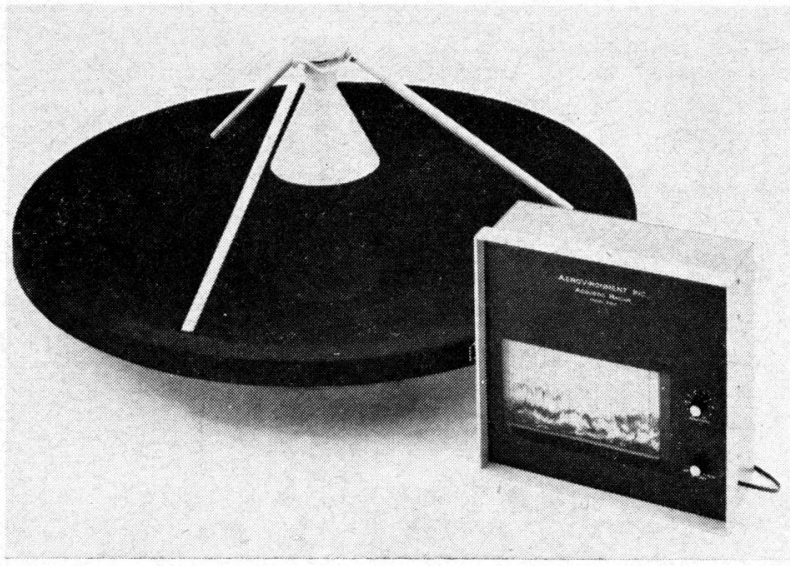

CATG. NO. 195 ACOUSTIC SOUNDER

When sound is propagated upward in the atmosphere, from a source that is colocated with a receiver, the intensity of the measured backscatter is related to small scale atmospheric temperature variations (similar to the manner in which a depth sounder identifies thermoclines in water). This is the principle of the Acoustic Sounder, sometimes referred to as Acoustic Radar. It is a ground based remote sounding system for acquiring data that can be used-to identify inversion heights; to detect layers of turbulence when there is a discontinuity in temperature; to outline the top of a layer of fog, or low clouds; to track wave motion; to measure convective plumes; and, to outline frontal surfaces. New applications are developing rapidly with experience, in techniques and equipment.

In the Model 300, which emits short bursts at 1,600 Hz., the sound source and the receiver are centered in a 4 -ft. diameter parabolic reflector. The sound that is backscattered from small scale temperature variations is recorded as a time-height plot of discontinuities above the instrument, presently to heights of about 1,000 meters.

A complete system consists of a parabolic antenna and transducer; a control module and recorder, operating at 115 V. $60 \mathrm{~Hz} .50 \mathrm{~W}$.; and an Acoustic Enclosure. System price, $\$ 6,950$. (without Enclosure, \$5,800). More details on request.

\section{Science Associates, Inc., 230 Nassau St., Princeton, N.J. 08540 (609) $924-4470$}

